\title{
Single Mini-Incision Total Hip Replacement for the Management of Arthritic Disease of the Hip
}

\author{
A Systematic Review and Meta-Analysis of Randomized Controlled Trials
}

\author{
Mari Imamura, PhD, Niall A. Munro, MD, FRCS(Tr\&Orth), Shihua Zhu, PhD, Cathryn Glazener, PhD, \\ Cynthia Fraser, MA, James Hutchison, FRCSEd, PhD, and Luke Vale, PhD \\ Investigation performed at the Health Services Research Unit, University of Aberdeen, Aberdeen, United Kingdom
}

\begin{abstract}
Background: Mini-incision total hip replacement continues the current trend in orthopaedics and other specialties toward smaller-incision surgery. The purpose of this systematic review was to assess the effectiveness and safety of single mini-incision compared with standard-incision total hip replacement for treatment of arthritis of the hip.
\end{abstract}

Methods: We conducted an electronic literature search for relevant studies published in any language up to March 2010. Key conference proceedings and national orthopaedic registries were searched, professional organizations and implant manufacturers were approached, and reference lists from included studies were screened. We included randomized and quasi-randomized controlled trials assessing single mini-incision surgery, defined as an incision of $\leq 10 \mathrm{~cm}$, compared with standard primary total hip replacement. Two reviewers independently assessed studies for inclusion and extracted data.

Results: Fifteen randomized and five quasi-randomized controlled trials, involving 1857 participants, were eligible. Included trials were of mixed methodological quality, with the sample size ranging from twenty to 219 . Mean follow-up periods were short, ranging from six weeks to three years. Compared with standard total hip replacement, mini-incision procedures may have small perioperative advantages in terms of less blood loss, shorter operative time, and shorter inpatient stay, but the differences were not clinically important. Few complications were reported, and the complication rate did not differ significantly between groups. There was insufficient evidence to suggest any major difference in the short-term revision rate, and confidence intervals for surrogate measures for long-term outcome were broad enough to include clinically important differences in favor of either approach.

Conclusions: Although there were marginal short-term advantages and disadvantages for each of the surgical techniques, there was no strong evidence either for or against mini-incision compared with standard-incision total hip replacement. Importantly, evidence on longer-term performance, especially the risk of revision arthroplasty, for mini-incision hip arthroplasty is very limited.

$\mathrm{H}$ ip replacement has been described as "the operation of the century"1,2 and is very successful in relieving pain and disability ${ }^{3}$. An estimated 226,000 primary hip replacements were performed in the United States in 2004, with a projected rise to over 600,000 by $2015^{4}$.

Following a general trend toward less invasive surgery in orthopaedics $^{5}$ and other surgical specialties ${ }^{6}$, there has been growing interest in minimally invasive total hip replacement through one or two mini-incisions. The precise definition of minimally invasive surgery is controversial, although it is com- monly defined in terms of an incision of $\leq 10 \mathrm{~cm}^{7}$. As with standard total hip replacement, substantial variations in the performance of mini-incision surgery, including the extent of deep dissection and the use of specifically designed instruments, exist among surgeons. Registry data suggest that the use of minimally invasive surgery for hip arthroplasty varies from $0.1 \%$ to $13 \%$ in different countries ${ }^{7-9}$.

It has been claimed that the majority of patients who are suitable for total hip replacement are also suitable for a minimal-incision procedure ${ }^{10}$. Minimal-incision surgery is,

Disclosure: One or more of the authors received payments or services, either directly or indirectly (i.e., via his or her institution), from a third party in support of an aspect of this work. In addition, one or more of the authors, or his or her institution, has had a financial relationship, in the thirty-six months prior to submission of this work, with an entity in the biomedical arena that could be perceived to influence or have the potential to influence what is written in this work. No author has had any other relationships, or has engaged in any other activities, that could be perceived to influence or have the potential to influence what is written in this work. The complete Disclosures of Potential Conflicts of Interest submitted by authors are always provided with the online version of the article. 
The Journal of Bone \& Joint Surgery $\cdot$ JbJS. org Volume 94-A • Number $20 \cdot$ OCtober 17, 2012

Single Mini-Incision Total Hip Replacement for the Management of Arthritic Disease of the Hip

TABLE I Summary of the Baseline Characteristics of the Included Studies*

\begin{tabular}{|c|c|c|c|c|c|c|}
\hline Study & $\begin{array}{l}\text { Operative Approach } \\
\text { (Mean Incision Length) }\end{array}$ & $\begin{array}{c}\text { No. of } \\
\text { Participants }\end{array}$ & Age $(y r)$ & $\operatorname{Sex}(M / F)$ & $\begin{array}{c}\mathrm{BMI} \\
\left(\mathrm{kg} / \mathrm{m}^{2}\right)\end{array}$ & $\begin{array}{l}\text { Mean or Median } \\
\text { Follow-up } \\
\text { [Range] (mo) }\end{array}$ \\
\hline \multirow[t]{3}{*}{ Charles $2006^{27} \dagger$} & & & & & & 3 \\
\hline & MI lateral & 20 & 66.6 & NR & 26 & \\
\hline & SI lateral & 20 & 70.8 & NR & 25 & \\
\hline \multirow[t]{2}{*}{ Chimento $2005^{21}$} & & & & & & 24 \\
\hline & SI posterolateral $(15 \mathrm{~cm})$ & 32 & 65.6 & $13 / 19$ & 25 & \\
\hline \multirow[t]{3}{*}{ Chung $2004^{22}$} & & & & & & $14.4[9.6-26.4]$ \\
\hline & MI posterolateral $(9 \mathrm{~cm})$ & 60 & 61.0 & $24 / 36$ & NR & \\
\hline & SI posterior $(20 \mathrm{~cm})$ & 60 & 64.0 & $28 / 32$ & NR & \\
\hline Dorr $2007^{38}$ & & & & & & 6 \\
\hline \multirow{2}{*}{ Dutka $2007^{33}$} & MI lateral $(6-8 \mathrm{~cm})$ & 60 & 46 & $10 / 50$ & 28 & \\
\hline & SI lateral $(20-25 \mathrm{~cm})$ & 60 & 44 & $12 / 48$ & 27 & \\
\hline \multirow[t]{3}{*}{ Farr $2008^{20} \dagger$} & & & & & & 12 \\
\hline & MI posterior & 97 & NR & NR & NR & \\
\hline & SI posterior & 119 & NR & NR & NR & \\
\hline \multirow[t]{3}{*}{ Hart $2005^{23}$} & & & 72.4 & $40 / 80$ & 28 & 39 [32.4-45.6] \\
\hline & MI posterolateral $(9-10 \mathrm{~cm})$ & 60 & & & & \\
\hline & SI posterolateral $(20 \mathrm{~cm})$ & 60 & & & & \\
\hline \multirow[t]{2}{*}{ Khan $2008^{28} \dagger$} & & & & & & 3 \\
\hline & $\mathrm{MI}(13 \mathrm{~cm})$ & 50 & NR & NR & NR & \\
\hline Kiyama $2008^{34}$ & SI posterolateral $(14 \mathrm{~cm})$ & 10 & 63.8 & $2 / 8$ & 24 & \\
\hline \multirow[t]{3}{*}{ Ogonda $2005^{19}$} & & & & & & 6 \\
\hline & MI posterior $(10 \mathrm{~cm})$ & 109 & 67.4 & $49 / 60$ & 28 & \\
\hline & $\mathrm{SI}$ posterior $(16 \mathrm{~cm})$ & 110 & 65.9 & $58 / 52$ & 29 & \\
\hline \multirow[t]{3}{*}{ Pneumaticos $2007^{29} \dagger$} & & & & & & $8[6-12]$ \\
\hline & MI posterior $(<10 \mathrm{~cm})$ & 25 & NR & $6 / 19$ & NR & \\
\hline & SI posterior $(16 \mathrm{~cm})$ & 27 & NR & $7 / 20$ & NR & \\
\hline \multirow[t]{3}{*}{ Pospischill $2010^{32}$} & & & & & & 3 \\
\hline & $\mathrm{MI}$ anterolateral $(8-10 \mathrm{~cm})$ & 20 & NR & NR & NR & \\
\hline & SI lateral & 20 & NR & NR & NR & \\
\hline \multirow[t]{3}{*}{ Pour $2007^{35}$} & & & & & & 1.5 \\
\hline & MI lateral $(10 \mathrm{~cm})$ & 50 & 61.6 & $21 / 23$ & 26 & \\
\hline & $\mathrm{SI}(14 \mathrm{~cm})$ & 50 & 60.1 & $27 / 23$ & 26 & \\
\hline \multirow[t]{3}{*}{ Rachbauer $2006^{30} \dagger$} & & & & & & NR \\
\hline & Ml anterior & 60 & NR & NR & NR & \\
\hline & SI lateral & 60 & NR & NR & NR & \\
\hline
\end{tabular}


TABLE I (continued)

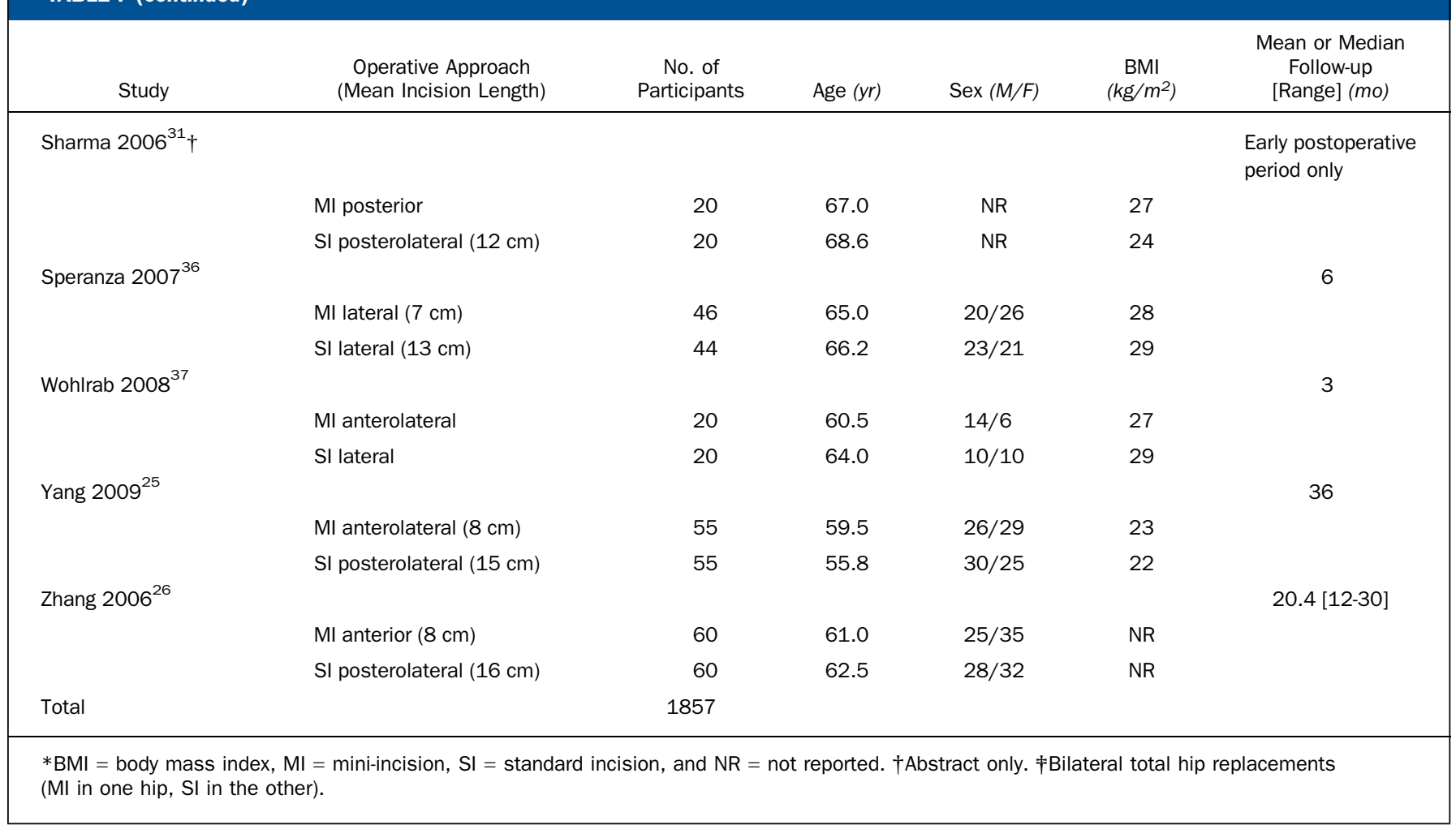

however, more difficult in patients who are obese or excessively muscular, as well as in patients with abnormal anatomy, previous hip surgery, or osteoporosis ${ }^{11}$.

Concern has been raised that commercial pressures and direct-to-consumer marketing rather than clinical evidence were largely responsible for the initial spread of mini-incision total hip replacement ${ }^{3,12,13}$. Therefore, we performed a systematic review of the literature with regard to the clinical effectiveness of mini-incision total hip replacement compared with standard total hip replacement for the management of arthritic disease of the hip.

\section{Materials and Methods \\ Search Strategy}

Cxtensive electronic searches were conducted in March 2010. The databases Esearched were MEDLINE, MEDLINE In-Process, Embase, BIOSIS, Science Citation Index, Cochrane Controlled Trials Register, National Research Register, Clinicaltrials.gov, Current Controlled Trials, Cochrane Database of Systematic Reviews, Database of Abstracts of Reviews of Effectiveness, HTA (Health Technology Assessment) database, and Health Management Information Consortium database. Full-text searching of key surgical journals was also undertaken. Web sites of national orthopaedic registries were searched, and key professional organizations and manufacturers were consulted. Searches were not restricted by study design, publication year, or language, and conference proceedings and abstracts were included. Reference lists of all included studies were scanned to identify additional potentially relevant studies. Full details of the MEDLINE and Embase search strategies used are documented in the Appendix and were adapted for other databases. Full details of all searches undertaken have been published elsewhere ${ }^{14}$.

\section{Study Selection, Data Extraction, and Assessment of Risk of Bias}

Two reviewers independently screened titles, abstracts, and full-text papers for eligibility, extracted data with use of a standard form, and evaluated the methodological quality with use of the Delphi criteria list ${ }^{15}$. Any disagreement was resolved by discussion or by consultation with a third reviewer. Authors were contacted in case of incompletely reported data.

We included randomized and quasi-randomized (alternating allocation) controlled trials of primary single mini-incision total hip replacement compared with standard total hip replacement for adults with arthritis. Single mini-incision surgery was defined as a procedure using one incision of $\leq 10 \mathrm{~cm}$, in accordance with the definition of the National Joint Registry for England and Wales in $2007^{16}$. Patients who underwent hip arthroplasty surgery for hip fracture or tumor, revision surgery, hip resurfacing, or surgery involving the use of individual computer-designed custom prostheses were excluded.

The primary outcome measures were the revision rate, postoperative dislocation rate, and surrogates for long-term outcomes. In the absence of studies using well-validated predictors of long-term outcome such as radiostereometry, we assessed implant position (quality of cup and stem placement), implant migration, and cementation quality as surrogate outcomes.

The secondary outcome measures were recovery after surgery (pain and resumption of normal activities), condition-specific quality of life (Harris hip score) and patient satisfaction, adverse effects (intraoperative blood loss, fracture, infection, nerve injury, deep venous thrombosis, heterotopic ossification, and mortality), and resource utilization (length of operation and length of hospital stay).

\section{Meta-Analysis}

Meta-analysis was performed if more than one identified study reported the same outcome. For dichotomous outcomes, a fixed-effect method was used to derive a summary estimate involving the Peto odds ratio (OR) and 
TABLE II Summary of Meta-Analyses for Surrogates of Long-Term Outcomes*

\begin{tabular}{|c|c|c|c|c|}
\hline Outcome & $\begin{array}{l}\text { No. of Studies (Participants) } \\
\text { Reporting the Outcome }\end{array}$ & $\begin{array}{l}\text { No. of Studies (Participants) } \\
\text { Informing the Meta-Analysis }\end{array}$ & Peto OR (95\% Cl) & $P$ Value \\
\hline Implant position, cups poorly placed & $5(614)$ & $3(454)$ & $0.87(0.48,1.58)$ & 0.65 \\
\hline Cement quality, poor & $3(389)$ & $2(269)$ & $1.26(0.70,2.27)$ & 0.45 \\
\hline Implant migration & $1 \dagger(120)$ & $0(0)$ & Not estimable & NA \\
\hline
\end{tabular}

accompanying 95\% confidence interval (CI). For continuous outcomes, a random-effects method was used to drive a weighted mean difference (WMD) and associated $95 \%$ CI. The Peto method was used for analysis of dichotomous outcomes because events were not particularly common for some of the prespecified outcomes. The random-effects method was chosen for analysis of continuous variables because of statistical heterogeneity as assessed with use of the chi-square test and $\mathrm{I}^{2}$ statistics ${ }^{17}$. Studies were excluded from the metaanalysis of the Peto OR if they had no events in both arms, as such studies provide no information about the direction or magnitude of relative treatment effects ${ }^{17}$. Meta-analysis was performed with use of the standard Cochrane Collaboration software RevMan version $5^{18}$. If a quantitative synthesis was not feasible, a narrative synthesis of the results was provided.

Meta-analysis of continuous variables requires means and standard deviations (SDs). However, some studies did not report the SD. Importantly, there seemed to be a greater tendency for the SD to be provided if the estimate was in a particular direction, and a meta-analysis performed only with studies that reported the SD might have generated biased results. For this reason, we chose to estimate missing SDs with use of a method recommended by the Cochrane Collaboration ${ }^{17}$ and using available information on $p$ values. This approach made the assumption that standard deviations were the same in both arms of the trial. If a study only reported $p$ values if they were less than a certain value (e.g., if $\mathrm{p}<0.05$ ), we calculated standard deviations on the basis of a $\mathrm{p}$ value equal to that value (e.g., $\mathrm{p}=0.05$ ).

\section{Source of Funding}

A previous version of this review ${ }^{14}$ was commissioned in 2006 by the United Kingdom NIHR (National Institute for Health Research) Health Technology Assessment program and the Canadian Agency for Drugs and Technologies in Health. No external funding was received for the present update.

\section{Results}

A total of twenty trials, reporting on 1857 participants, were A identified. The flow of trials through the study selection process is shown in the Appendix. Only two trials ${ }^{19,20}$ had $>200$ participants. The other trials ranged in size from twenty to 120 . The mean duration of follow-up was also short, ranging from six weeks to three years, with only seven trials ${ }^{20-26}$ having a mean follow-up duration of one year or longer (Table I). Six trials were published only as abstracts ${ }^{20,27-31}$.

The included studies were of mixed methodological quality (see Appendix). Allocation concealment was adequate in four studies $(20 \%)^{19,21,26,32}$ and inadequate (quasi-randomization through alternating allocation) in five $(25 \%)^{22-24,33,34}$, but the other eleven studies ${ }^{20,25,27-31,35-38}(55 \%)$ provided insufficient information for this to be assessed.

Hip replacements were performed with use of several approaches (Table I). The authors of five trials indicated that total hip replacement was performed by "experienced" surgeons ${ }^{19,21,23,29,34}$, whereas two ${ }^{22,36}$ suggested that the mini-incision procedure represented surgeons' early experience with this technique. Surgeons' experience with the mini-incision approach was not reported for the remaining trials. The rehabilitation protocols that were used differed across trials but were consistent within individual trials. It was also explicitly stated in nine trials $^{21-23,25,26,30,32,35,37}$ that patients with higher body mass indices (BMIs) were excluded.

\section{Meta-Analysis}

\section{Revision Rate and Surrogates for Long-Term Outcomes}

Three trials $s^{1,21,23}$ reported the number of patients requiring revision surgery, but only one patient underwent such surgery. Hence, confidence intervals were very wide and included differences that were not clinically plausible (one of 197 compared with zero of 198 resulted in a Peto OR of 7.96 with a $95 \%$ CI of 0.16 to 402.02 [ $p=0.30]$; see Appendix).

No trend favoring either treatment group was discernible in any of the prespecified surrogate measures (Table II and Appendix). The confidence intervals were wide and include clinically important differences favoring either approach.

\section{Postoperative Dislocation Rates}

Dislocation was also uncommon, occurring at a rate of $<1 \%$ in both surgical techniques. There were no clear differences between groups and confidence intervals were wide, including differences that were not clinically plausible (Peto OR, 1.23; $95 \% \mathrm{CI}, 0.38$ to $4.05 ; \mathrm{p}=0.73$; Fig. 1 ).

\section{Recovery After Surgery}

Much of the available data on the level of pain and resumption of normal activities after surgery were derived within three months of surgery (see Appendix). Outcome measures differed among studies, making the results difficult to combine. On average, results were slightly more favorable for the mini-incision group, although few studies reported any statistically significant differences between the groups. Differences over longer terms were sparsely reported (see Appendix).

\section{Condition-Specific Quality of Life and Patient Satisfaction}

Meta-analysis showed that the Harris hip score at three months or less after mini-incision surgery was better than that after 
1901

The Journal of Bone \& Joint Surgery JbjS. org Volume 94-A • Number 20 - October 17, 2012
Single Mini-Incision Total Hip Replacement for the

Management of Arthritic Disease of the Hip

\begin{tabular}{|c|c|c|c|c|c|c|c|c|c|}
\hline \multirow[b]{2}{*}{ Study or Subgroup } & \multicolumn{2}{|c|}{ Mini-incision (MI) } & \multicolumn{2}{|c|}{ Standard incision (SI) } & \multirow[b]{2}{*}{ Weight } & \multirow{2}{*}{$\begin{array}{l}\text { Peto Odds Ratio } \\
\text { Peto, Fixed, } 95 \% \mathrm{Cl}\end{array}$} & \multirow{2}{*}{\multicolumn{3}{|c|}{$\begin{array}{l}\text { Peto Odds Ratio } \\
\text { Peto, Fixed, } 95 \% \text { CI }\end{array}$}} \\
\hline & Events & Total & Events & Total & & & & & \\
\hline Chimento 2005 & 2 & 28 & 0 & 32 & $18.0 \%$ & $8.84[0.54,145.71]$ & & & \\
\hline Chung 2004 & 0 & 60 & 0 & 60 & & Not estimable & & & \\
\hline Dorr 2007 & 0 & 30 & 0 & 30 & & Not estimable & & & \\
\hline Dutka 2007 & 0 & 60 & 0 & 60 & & Not estimable & & & \\
\hline Hart 2005 & 1 & 60 & 1 & 60 & $18.3 \%$ & $1.00[0.06,16.18]$ & & & \\
\hline Khan 2008 & 0 & 50 & 1 & 50 & $9.2 \%$ & $0.14[0.00,6.82]$ & & & \\
\hline Kim 2006 & 1 & 70 & 1 & 70 & $18.3 \%$ & $1.00[0.06,16.15]$ & & & \\
\hline Ogonda 2005 & 1 & 109 & 1 & 110 & $18.3 \%$ & $1.01[0.06,16.24]$ & & & \\
\hline Pospischill 2010 & 1 & 20 & 1 & 20 & $17.9 \%$ & $1.00[0.06,16.58]$ & & & \\
\hline Pour 2007 & 0 & 44 & 0 & 50 & & Not estimable & & & \\
\hline Sharma 2006 & 0 & 20 & 0 & 20 & & Not estimable & & & \\
\hline Speranza 2007 & 0 & 46 & 0 & 54 & & Not estimable & & & \\
\hline Wohlrab 2008 & 0 & 20 & 0 & 20 & & Not estimable & & & \\
\hline Yang 2009 & 0 & 55 & 0 & 55 & & Not estimable & & & \\
\hline Total $(95 \% \mathrm{Cl})$ & & 672 & & 691 & $100.0 \%$ & $1.23[0.38,4.05]$ & & & \\
\hline Total events & 6 & & 5 & & & & & & \\
\hline $\begin{array}{l}\text { Heterogeneity: } \mathrm{Chi}^{2}= \\
\text { Test for overall effect: }\end{array}$ & $\begin{array}{l}21, d f=5 \\
=0.35(P\end{array}$ & $\begin{array}{l}0.67) \text {; } \\
\text { 73) }\end{array}$ & $I^{2}=0 \%$ & & & & 0.001 & $\begin{array}{ccc}0.1 & 1 & 10 \\
\text { Favors } & 1 & \\
1 & \text { Favors SI }\end{array}$ & 1000 \\
\hline
\end{tabular}

Fig. 1

Postoperative dislocation. $\mathrm{Cl}=$ confidence interval, and $\mathrm{df}=$ degrees of freedom.

standard-incision surgery, but the difference was small and not significant (WMD, 4.31; 95\% CI, 0.08 to 8.54; $\mathrm{p}=0.05$; Fig. 2). Three studies ${ }^{33,36,38}$ with data that could not be included in the meta-analysis also revealed no evidence of a difference between groups (see Appendix). All but one $e^{20}$ of the ten trials ${ }^{20-22,24-26,29,33,36,38}$ that followed participants over a longer term (greater than three months) indicated that there were no significant differences between the groups, but the data in few of these trials were suitable for formal meta-analysis (see Appendix).

One small trial' ${ }^{27}(\mathrm{~N}=27)$ indicated that patient satisfaction scores were slightly lower in the standard incision group (14.6) than in the mini-incision group (15.2), but the difference was not significant $(\mathrm{p}=0.341)$.

\section{Short-Term Complications}

Meta-analysis showed evidence of less blood loss (by approximately $65 \mathrm{~mL}$ ) in the mini-incision group than in the standardincision group (WMD, $-65 \mathrm{~mL} ; 95 \% \mathrm{CI},-98$ to $-33 \mathrm{~mL}$; $\mathrm{p}<$
0.0001; Fig. 3 and Appendix). However, the difference was not clinically important.

Adverse events during the postoperative period were uncommon in the included studies. No significant differences emerged between mini-incision and standard-incision procedures with respect to prespecified adverse effect measures (Table III and Appendix). This may be due to the fact that all of the trials were small and underpowered. In general, mini-incision procedures had higher rates of infections and nerve injury but lower rates of fractures, deep venous thrombosis, and heterotopic ossification compared with standard procedures.

The authors of one $\operatorname{trial}^{19}$ reported that two $(2 \%)$ of the 110 patients in the standard-incision group had died in the early postoperative period; one patient with ischemic heart disease who had undergone a previous angioplasty had an acute myocardial infarction, and the other had extensive bowel infarction due to mesenteric vessel thrombosis. The authors of another $\operatorname{trial}^{28}$ reported one death in the mini-incision group from pulmonary embolism.



Fig. 2

Harris hip score (obtained at $\leq 3$ months), including studies in which standard deviations were estimated from the reported $\mathrm{p} \mathrm{value}$. $\mathrm{Cl}=\mathrm{confidence} \mathrm{interval,}$ $\mathrm{IV}=$ inverse variance, and $\mathrm{df}=$ degrees of freedom. 
1902

The Journal of Bone \& Joint Surgery $\cdot$ JBjS. org Volume 94-A • Number 20 - OCtober 17, 2012

Single Mini-Incision Total Hip Replacement for the

Management of Arthritic Disease of the Hip

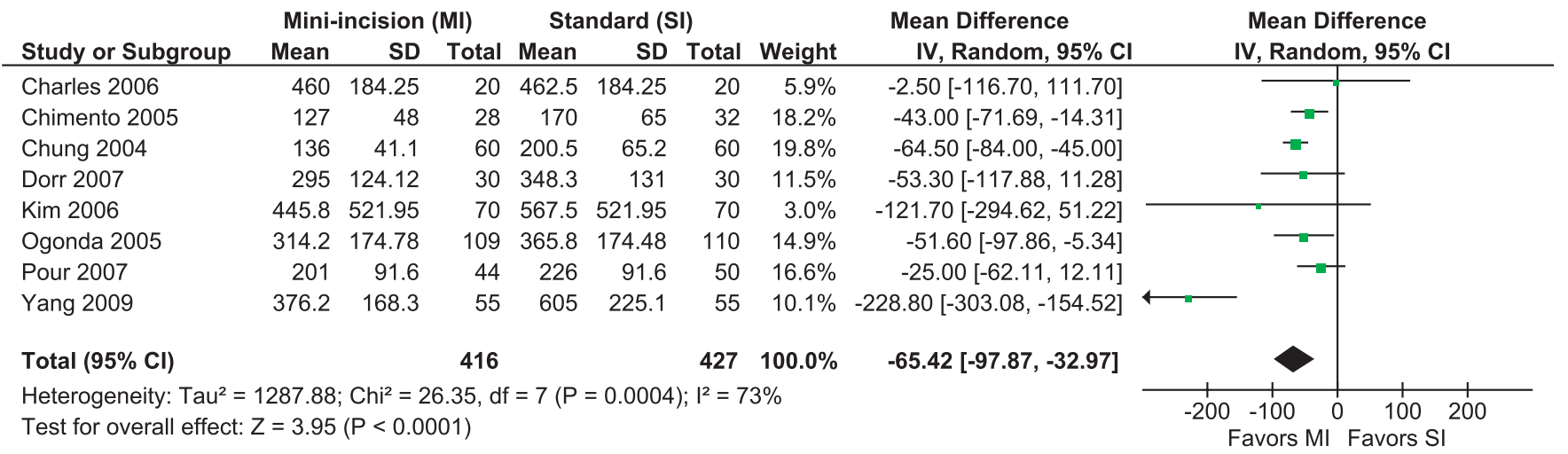

Fig. 3

Intraoperative blood loss (in $\mathrm{mL}$ ), including studies in which standard deviations were estimated from the reported $\mathrm{p} \mathrm{value.} \mathrm{Cl}=\mathrm{confidence}$ interval,

$\mathrm{IV}=$ inverse variance, and $\mathrm{df}=$ degrees of freedom.

Resource Utilization

The results of the meta-analysis suggested that the operative time for mini-incision surgery may be slightly shorter, by approximately two minutes (WMD, -2 minutes; $95 \% \mathrm{CI},-6$ to 2 minutes; $\mathrm{p}=0.33$; Fig. 4). The difference was not significant and not clinically relevant.

The mean length of hospital stay was shorter in the miniincision group (WMD, -0.3 day; $95 \% \mathrm{CI},-0.7$ to 0.1 day; $\mathrm{p}=$
0.18; Fig. 4). However, this must be interpreted with caution, since these differences may reflect the clinical policy of each hospital for discharge rather than the clinical need of each patient.

The results of other studies with data that could not be included in the meta-analyses (eight for operative time $\mathrm{e}^{20,23,28-31,36,37}$ and seven for length of hospital stay ${ }^{20,26,28,29,31,33,36}$ ) were consistent with these findings (see Appendix).

\begin{tabular}{|c|c|c|c|c|c|c|c|c|c|c|c|}
\hline Study or Subgroup & \multicolumn{3}{|c|}{ Mini-incision (MI) } & \multicolumn{3}{|c|}{ Standard incision (SI) } & Weight & $\begin{array}{l}\text { Mean Difference } \\
\text { IV, Random, } 95 \% \mathrm{Cl}\end{array}$ & \multicolumn{3}{|c|}{$\begin{array}{c}\text { Mean Difference } \\
\text { IV, Random, } 95 \% \mathrm{Cl}\end{array}$} \\
\hline Charles 2006 & 95.2 & 23.29 & 20 & 87.7 & 23.29 & 20 & $4.8 \%$ & $7.50[-6.94,21.94]$ & & & \\
\hline Chung 2004 & 49 & 9.4 & 60 & 55.1 & 17.9 & 60 & $10.3 \%$ & $-6.10[-11.22,-0.98]$ & & & \\
\hline Dorr 2007 & 99.69 & 24.57 & 30 & 110.67 & 40.61 & 30 & $3.9 \%$ & $-10.98[-27.96,6.00]$ & $\leftarrow$ & & \\
\hline Dutka 2007 & 118 & 16 & 60 & 133 & 18 & 60 & $9.6 \%$ & $-15.00[-21.09,-8.91]$ & & & \\
\hline Ogonda 2005 & 60.3 & 9.2 & 109 & 65.9 & 13.2 & 110 & $11.5 \%$ & $-5.60[-8.61,-2.59]$ & & & \\
\hline Pour 2007 & 52.6 & 11.33 & 44 & 50 & 11.33 & 50 & $10.6 \%$ & $2.60[-1.99,7.19]$ & & & \\
\hline Yang 2009 & 77.6 & 13.4 & 55 & 73.7 & 14.5 & 55 & $10.2 \%$ & $3.90[-1.32,9.12]$ & & & \\
\hline $\begin{array}{l}\text { Zhang } 2006 \\
\text { Subtotal }(95 \% \mathrm{Cl})\end{array}$ & 75 & 16.6 & $\begin{array}{r}60 \\
546\end{array}$ & 69 & 16.6 & $\begin{array}{r}60 \\
557\end{array}$ & $\begin{array}{r}9.7 \% \\
100.0 \%\end{array}$ & $\begin{array}{r}6.00[0.06,11.94] \\
-2.00[-6.02,2.03]\end{array}$ & & & \\
\hline \multicolumn{12}{|c|}{$\begin{array}{l}\text { Heterogeneity: } \mathrm{Tau}^{2}=34.19 ; \mathrm{Chi}^{2}=54.27, \mathrm{df}=10(P<0.00001) ; \mathrm{I}^{2}=82 \% \\
\text { Test for overall effect: } \mathrm{Z}=0.97(\mathrm{P}=0.33)\end{array}$} \\
\hline Chimento 2005 & 5.8 & 2.2 & 28 & 5.5 & 2.2 & 32 & $8.7 \%$ & $0.30[-0.82,1.42]$ & & & \\
\hline Chung 2004 & 4.41 & 1.1 & 60 & 5.34 & 1.4 & 60 & $20.5 \%$ & $-0.93[-1.38,-0.48]$ & - & & \\
\hline Dorr 2007 & 2.63 & 0.55 & 30 & 3.07 & 0.98 & 30 & $21.6 \%$ & $-0.44[-0.84,-0.04]$ & & & \\
\hline Ogonda 2005 & 3.65 & 2.04 & 109 & 3.68 & 2.45 & 110 & $17.1 \%$ & $-0.03[-0.63,0.57]$ & & & \\
\hline $\begin{array}{l}\text { Pour } 2007 \\
\text { Subtotal }(95 \% \mathrm{Cl})\end{array}$ & 3.92 & 0.93 & $\begin{array}{r}44 \\
291\end{array}$ & 3.79 & 0.93 & $\begin{array}{r}50 \\
302\end{array}$ & $\begin{array}{r}22.2 \% \\
100.0 \%\end{array}$ & $\begin{array}{r}0.13[-0.25,0.51] \\
-0.27[-0.67,0.13]\end{array}$ & & & \\
\hline \multicolumn{12}{|c|}{$\begin{array}{l}\text { Heterogeneity: } \mathrm{Tau}^{2}=0.15 ; \mathrm{Chi}^{2}=14.88, \mathrm{df}=5(P=0.01) ; \mathrm{I}^{2}=66 \% \\
\text { Test for overall effect: } Z=1.33(P=0.18)\end{array}$} \\
\hline & & & & & & & & & $\begin{array}{l}-10 \quad 0 \\
\text { Favors } \mathrm{Ml}\end{array}$ & Favors SI & 20 \\
\hline
\end{tabular}

Fig. 4

Length of the operation (in minutes) and length of the hospital stay (in days), including studies in which standard deviations were estimated from the reported $\mathrm{p}$ value $\mathrm{Cl}=$ confidence interval, $\mathrm{IV}=$ inverse variance, $\mathrm{SD}=$ standard deviation, and $\mathrm{df}=$ degrees of freedom. 
TABLE III Summary of Meta-Analyses for Short-Term Complications

\begin{tabular}{|c|c|c|c|c|}
\hline Outcome & $\begin{array}{l}\text { No. of Studies (Participants) } \\
\text { Reporting the Outcome }\end{array}$ & $\begin{array}{l}\text { No. of Studies (Participants) } \\
\text { Informing the Meta-Analysis }\end{array}$ & Peto OR $(95 \% \mathrm{Cl}) *$ & $P$ Value \\
\hline Intraoperative fracture & $7(763)$ & $1(219)$ & $0.14(0.01,2.18)$ & 0.16 \\
\hline Infection & $13(1383)$ & $3(459)$ & $2.74(0.38,19.47)$ & 0.31 \\
\hline Nerve injury & $11(1064)$ & $3(280)$ & $3.58(0.62,20.85)$ & 0.16 \\
\hline
\end{tabular}

\section{Discussion}

$\mathrm{C}$ urrent evidence suggests that differences between miniincision and standard total hip replacement with respect to surgical time and blood loss are of little clinical importance. There was a statistically nonsignificant trend toward a shorter length of hospital stay, although studies were inconsistent and the differences were small. Differences in disease-specific outcome measures varied among studies but there was generally little difference between the groups. The number of reported complications in both groups was small and there was no significant difference between groups, although there was a tendency toward increased infections and nerve injuries and decreased fractures and deep venous thromboses in the mini-incision group. There were no major differences in the short-term revision rate or surrogates for long-term outcome measures, although no studies are yet able to report long-term revision rates or outcomes. Overall, there is no strong evidence either for or against mini-incision compared with standardincision total hip replacement on the basis of the short-term measures currently available.

Many studies (nine ${ }^{21-23,25,26,30,32,35,37}$ of the eleven trials that reported inclusion criteria) excluded patients with higher BMIs, and care should be taken in extrapolating study findings to more heterogeneous patient groups. In addition, most of the studies were presumably undertaken by surgeons or groups with particular expertise in hip surgery, and it is uncertain whether the low complication rates reported here could be reproduced more widely, particularly during a surgeon's initial "learning curve." 39,40

The definition of minimally invasive surgery is problematic. Incision length is commonly used because it is easily quantified, but it may correlate poorly with the extent of deep dissection and overall tissue trauma. This might partially explain the small size of the differences between groups.

We conducted thorough literature searches and applied current best practice for undertaking systematic reviews ${ }^{17}$. However, the review was limited by the small size, short follow-up, and quality of the primary studies. The lack of data unfortunately made it necessary to combine a range of different surgical approaches, implants, and rehabilitation protocols in one group. A mini-incision procedure may reduce visualization for component positioning. Its relative merits must therefore be measured over a longer term to show that the proven longevity of total hip arthroplasty is not compromised by the use of a smaller incision. However, reported revision rates during the follow-up periods (maximum mean, three years) were $0.5 \%$ (one of 197) for miniincision procedures compared with $0 \%$ (zero of 198) for standard procedures. Clearly, such a small number of revisions does not provide any indication as to which procedure is associated with a higher risk and the magnitude of this risk elevation.

The results may have been further confounded by inadequate conduct and reporting of the trials. In particular, lack of allocation concealment in five of the twenty trials, which used quasi-randomization (alternation), and incomplete reporting of the concealment method in an additional eleven trials could have introduced selection bias and exaggerated estimates of the intervention effect ${ }^{41}$. A large proportion of the studies did not report measures of variability (SD) needed for meta-analysis of continuous data. To minimize the resulting bias, we used a standard method to impute a missing SD value from the stated $p$ value for the difference between the means. This could have caused summary estimates to be overly precise. The variability in the outcome measures used, especially those assessing recovery after surgery and quality of life, also made comparison across studies difficult.

Despite the absence of a clear difference between minimally invasive and standard hip replacement, we believe that this meta-analysis has important implications. First, it suggests that strong claims either for or against well-conducted singleincision minimally invasive surgery on the basis of small individual studies are not justified. Second, it demonstrates that, despite the multitude of papers on minimally invasive surgery, there is still a need for well-conducted studies with adequate sample sizes and follow-up. It also highlights the importance of standardized outcome measures and adherence to standard guidance for reporting ${ }^{42}$ to enable robust synthesis of research evidence.

In conclusion, this review suggests that the short-term results of mini-incision total hip replacement are not notably different from those of standard total hip replacement. Importantly, 
The Journal of Bone \& Joint Surgery - jbjs.org Volume 94-A • Number 20 - October 17, 2012
Single Mini-Incision Total Hip Replacement for the Management of Arthritic Disease of the Hip there is a lack of data on longer-term performance, and especially on the revision rate. Although there may be some marginal shorter-term advantages and disadvantages, the current evidence is not strong enough to support one surgical technique over the other.

\section{Appendix}

eA Tables summarizing search strategy, the risk of bias, recovery after surgery, quality of life, blood loss, length of the operation, and length of the hospital stay in the included studies as well as figures showing the study selection flow chart and meta-analyses of the revision rate, surrogates for long-term outcome, and short-term complications are available with the online version of this article as a data supplement at jbjs.org. NoTE: This review was part of a larger study conducted by the Aberdeen and Ottawa Health Technology Assessment (HTA) Team. Other members of the HTA team are Robyn de Verteuil (Hearth Grant (Institute of Applied Health Sciences, University of Aberdeen, UK), Douglas Coyle (Department of Epidemiology and Community Medicine, University of Ottawa, and Coyle Consultancy, Canada), and Kathryn Coyle (Coyle Consultancy, Canada). The authors thank Stephan Dombrowski for German translation, Shirley Xia for Chinese translation, and Bronwyn Davidson and Kathleen McIntosh for secretarial support. The Health Services Research Unit is core funded by the Chief Scientist Office of the Scottish Executive Health Department. The views expressed are those of the authors.
Mari Imamura, $\mathrm{PhD}$

Shihua Zhu, PhD

Cathryn Glazener, $\mathrm{PhD}$

Cynthia Fraser, MA

Luke Vale, $\mathrm{PhD}$

Health Services Research Unit,

University of Aberdeen,

Health Sciences Building, Foresterhill,

Aberdeen AB25 2ZD, United Kingdom.

E-mail address for M. Imamura: m.imamura@abdn.ac.uk

Niall A. Munro, MD, FRCS(Tr\&Orth)

Golden Jubilee National Hospital,

Agamemnon Street,

Clydebank G81 4DY, United Kingdom

James Hutchison, FRCSEd, PhD

Department of Orthopaedics,

University of Aberdeen,

Foresterhill, Aberdeen AB25 2ZD,

United Kingdom

\section{References}

1. Coventry MB. Foreword. In: Amstutz HC, editor. Hip arthroplasty. New York: Churchill Livingstone; 1991.

2. Learmonth ID, Young $C$, Rorabeck $C$. The operation of the century: total hip replacement. Lancet. 2007 Oct 27;370(9597):1508-19.

3. McGrory B, Callaghan J, Kraay M, Jacobs J, Robb W, Wasielewski R, Brand RA. Editorial: minimally invasive and small-incision joint replacement surgery: what surgeons should consider. Clin Orthop Relat Res. 2005 Nov;440:251-4.

4. Kim S. Changes in surgical loads and economic burden of hip and knee replacements in the US: 1997-2004. Arthritis Rheum. 2008 Apr 15;59(4):481-8. 5. Hunt D. Minimal access orthopaedics. Oxford: Radcliffe Medical Press; 1995. 6. Darzi A, Mackay S. Recent advances in minimal access surgery. BMJ. 2002 Jan 5;324(7328):31-4.

7. National joint registry for England and Wales. 7th annual report 2010. Hemel Hempstead: National Journal Registry Centr; 2010. http://www.njrcentre.org.uk/ NjrCentre/LinkClick.aspx?fileticket $=$ QkPI7kk6B2E\%3d\&tabid $=86 \& \mathrm{mid}=52$. Accessed 2011 Jan.

8. Hip and knee replacements in Canada. 2008-2009 annual report. Canadian Joint Replacement Registry. Ottawa: Canadian Institute for Health Information; 2009. https://secure.cihi.ca/estore/productFamily.htm?pf=PFC1063\&lang= en\&media $=0$. Accessed 2012 Jul 23.

9. Report 2008. Centre of excellence of joint replacements. The Norwegian Arthroplasty Register. The Norwegian Cruciate Ligament Register. The Norwegian Hip Fracture Register. Bergen, Norway: Haukeland University Hospital Department of Orthopedic Surgery; 2008. http://nrlweb.ihelse.net/eng/Report2008.pdf. Accessed 2011 Jan

10. Berger RA. Mini-incision total hip replacement using an anterolateral approach: technique and results. Orthop Clin North Am. 2004 Apr;35(2):143-51.

11. Ranawat CS, Ranawat $A S$. Minimally invasive total joint arthroplasty: where are we going? J Bone Joint Surg Am. 2003 Nov;85-A(11):2070-1.

12. Hungerford DS. Minimally invasive total hip arthroplasty: in opposition. J Arthroplasty. 2004 Jun;19(4 Suppl 1):81-2.

13. Ranawat CS, Ranawat AS. A common sense approach to minimally invasive total hip replacement. Orthopedics. 2005 Sep;28(9):937-8.

14. de Verteuil R, Imamura M, Zhu S, Glazener C, Fraser C, Munro N, Hutchison J, Grant A, Coyle D, Coyle K, Vale L. A systematic review of the clinical effectiveness and cost-effectiveness and economic modelling of minimal incision total hip replacement approaches in the management of arthritic disease of the hip. Health Technol Assess. 2008 Jun;12(26):iii-iv, ix-223.

15. Verhagen AP, de Vet HC, de Bie RA, Kessels AG, Boers M, Bouter LM, Knipschild PG. The Delphi list: a criteria list for quality assessment of randomized clinical trials for conducting systematic reviews developed by Delphi consensus. J Clin Epidemiol. 1998 Dec;51(12):1235-41.

16. National joint registry for England and Wales. 4th Annual Report. Hemel Hempstead: National Journal Registry Centre; 2007. http://www-new.njrcentre.org.uk/NjrCentre/
LinkClick.aspx?fileticket $=8 y m 2 z 0 o R f v w \% 3 d \& t a b i d=86 \&$ mid $=523$. Accessed 2011 Jan.

17. Higgins JP, Green S. Cochrane handbook for systematic reviews of interventions. Version 5.1.0. The Cochrane Collaboration; 2011. http://www.cochranehandbook.org/. Accessed 2011 Jan.

18. Review Manager (RevMan). Version 5.0. Copenhagen: The Nordic Cochrane Centre, The Cochrane Collaboration; 2008. http://ims.cochrane.org/revman. Accessed 2011 Jan.

19. Ogonda L, Wilson R, Archbold P, Lawlor M, Humphreys P, O'Brien S, Beverland D. A minimal-incision technique in total hip arthroplasty does not improve early postoperative outcomes. A prospective, randomized, controlled trial. J Bone Joint Surg Am. 2005 Apr;87(4):701-10.

20. Farr DJ, Conn KS, Britton JM, Calder JD, Stranks GJ. Single incision posterior approach minimally invasive total hip arthroplasty is a safe, effective and reproducible technique in a district general hospital. A randomised control trial. Presented at the British Hip Society Annual Meeting; 2008 Feb 27-29; Norwich, England. 21. Chimento GF, Pavone V, Sharrock N, Kahn B, Cahill J, Sculco TP. Minimally invasive total hip arthroplasty: a prospective randomized study. J Arthroplasty. 2005 Feb;20(2):139-44.

22. Chung WK, Liu D, Foo LS. Mini-incision total hip replacement-surgical technique and early results. J Orthop Surg (Hong Kong). 2004 Jun;12(1):19-24.

23. Hart R, Stipcák V, Janecek M, Visna P. Component position following total hip arthroplasty through a miniinvasive posterolateral approach. Acta Orthop Belg. 2005 Feb; $71(1): 60-4$.

24. Kim YH. Comparison of primary total hip arthroplasties performed with a minimally invasive technique or a standard technique: a prospective and randomized study. J Arthroplasty. 2006 Dec;21(8):1092-8.

25. Yang $\mathrm{Y}$, Zheng $\mathrm{P}$, Han J- X. [Modified minimally invasive total hip arthroplasty through a lateral approach in 43 cases]. J Clin Rehab Tissue Eng Res. 2009;13:1743-6. Chinese.

26. Zhang $X L$, Wang $Q$, Jiang $Y$, Zeng BF. [Minimally invasive total hip arthroplasty with anterior incision]. Zhonghua Wai Ke Za Zhi. 2006 Apr 15;44(8):512-5. Chinese. 27. Charles MN, Fejbel RJ, Kim P. Minimally invasive surgery of the hip - a randomized pilot study. Presented at the Annual Meeting of the Canadian Orthopaedic Association; 2006 Jun 2-4; Toronto. Poster 88.

28. Khan RJ, Haebich S, Maor D. Minimally invasive hip replacement - a randomised controlled trial. Presented at the British Hip Society Annual Meeting; 2008 Feb 27-29; Norwich, England.

29. Pneumaticos S, Nikolaou V, Savvidou C, Tsiolis P. Comparison of primary total hip replacements performed with a standard posterior incision or a posterior miniincision. Presented at the European Federation of National Associations of Orthopaedics and Traumatology, 8th Annual Congress. 2007 May 11-15; Florence. 30. Rachbauer F, Rosiek R, Nogler M, Kessler $\mathrm{O}$. The benefits of the direct anterior approach in minimally invasive THA. Presented at the Annual Meeting of the American Academy of Orthopaedic Surgeons; 2006 Mar; Chicago. Paper No 202. 
The JOURNAL OF BONE \& JOINT SURGERY • JBJS.ORG Volume 94-A · Number 20 - OCTOBER 17, 2012
Single Mini-Incision Total Hip Replacement for the Management of Arthritic Disease of the Hip
31. Sharma S, Bhamra MS. A prospective randomised pilot study to compare early post-operative recovery after conventional versus minimal incision posterior approach for total hip joint replacement. J Bone Joint Surg Br. 2006; 88B:243.

32. Pospischill M, Kranzl A, Attwenger B, Knahr K. Minimally invasive compared with traditional transgluteal approach for total hip arthroplasty: a comparative gait analysis. J Bone Joint Surg Am. 2010 Feb;92(2):328-37.

33. Dutka J, Sosin P, Libura M, Skowronek P. Total hip arthroplasty through a minimally invasive lateral approach-our experience and early results. Ortop Traumatol Rehabil. 2007 Jan-Feb;9(1):39-45.

34. Kiyama $T$, Naito M, Shitama $H$, Shinoda $T$, Maeyama A. Comparison of skin blood flow between mini- and standard-incision approaches during total hip arthroplasty. J Arthroplasty. 2008 Oct;23(7):1045-9. Epub 2008 Mar 4.

35. Pour AE, Parvizi J, Sharkey PF, Hozack WJ, Rothman RH. Minimally invasive hip arthroplasty: what role does patient preconditioning play? J Bone Joint Surg Am. 2007 Sep;89(9):1920-7.

36. Speranza A, lorio R, Ferretti M, D'Arrigo C, Ferretti A. A lateral minimal-incision technique in total hip replacement: a prospective, randomizes, controlled trial. Hip Int. 2007 Jan-Mar;17(1):4-8.
37. Wohlrab D, Droege JW, Mendel T, Brehme K, Riedl K, Leuchte S, Hein W. [Minimally invasive vs. transgluteal total hip replacement. A 3-month follow-up of a prospective randomized clinical study]. Orthopade. 2008 Nov;37(11):1121-6. German. 38. Dorr LD, Thomas D, Long WT, Polatin PB, Sirianni LE. Psychologic reasons for patients preferring minimally invasive total hip arthroplasty. Clin Orthop Relat Res. 2007 May;458:94-100.

39. Laffosse JM, Chiron P, Accadbled F, Molinier F, Tricoire JL, Puget J. Learning curve for a modified Watson-Jones minimally invasive approach in primary total hip replacement: analysis of complications and early results versus the standardincision posterior approach. Acta Orthop Belg. 2006 Dec;72(6):693-701.

40. Fehring TK, Odum S, Griffin WL, Mason JB. Outcome comparison of partial and full component revision TKA. Clin Orthop Relat Res. 2005 Nov;440:131-4.

41. Wood L, Egger M, Gluud LL, Schulz KF, Jüni P, Altman DG, Gluud C, Martin RM, Wood AJ, Sterne JA. Empirical evidence of bias in treatment effect estimates in controlled trials with different interventions and outcomes: meta-epidemiological study. BMJ. 2008 Mar 15;336(7644):601-5. Epub 2008 Mar 3.

42. CONSORT (Consolidated Standards of Reporting of Trials). The CONSORT statement. http://www.consort-statement.org/consort-statement/overview0/. Accessed 2011 Jan. 